
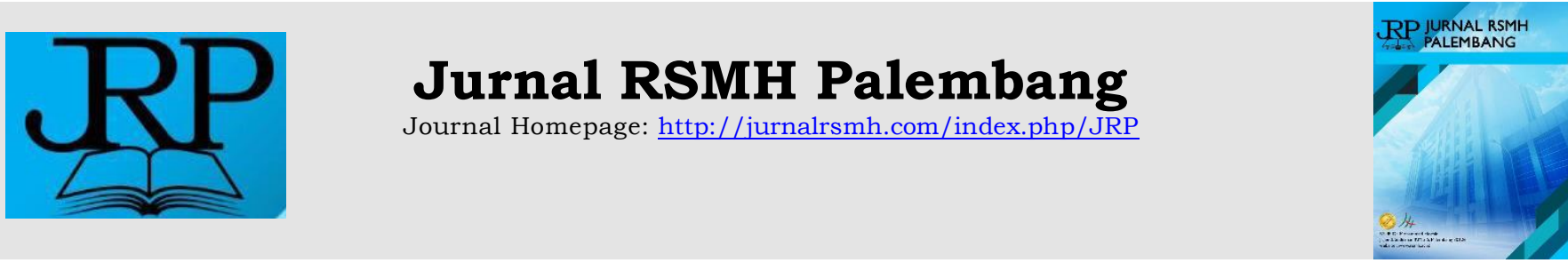

\title{
Stromal Tumors in the Prostate
}

\section{Kurniawan Dedy, Aspitriani}

Department of Anatomical Pathology, Faculty of Medicine, Sriwijaya University, Palembang, Indonesia

\author{
A R T I C L E I N F O \\ Keywords: \\ Stromal Tumor \\ Prostate Tumor \\ Prostate Stump \\ PSS \\ Tromal Sarcoma

\section{Corresponding author: Aspitriani \\ E-mail address: Aspitriani Aspitriani@gmail.com}

All authors have reviewed and approved the final version of the manuscript.

https://doi.org/10.37275/JRP.v1i1.2

\begin{abstract}
A B S T R A C T
Stromal tumors of the prostate are rare mesenchymal tumors of the prostate stroma, in the form of spindle cell tumors, which are differentiated by cellularity, mitotic index, cellular atypia, and necrosis. These tumors are classified into two; prostatic stromal tumors of uncertain malignant potential (STUMP) and prostatic stromal sarcomas (PSS). The incidence is about $0.1-0.2 \%$ of the total incidence of prostate cancer. The pathogenesis of prostate stromal tumors is based on origin, clonal and chromosomal abnormalities. Clinical symptoms of complaints lead to lower urinary tract obstruction, dysuria and pollakiuria as well as abnormalities in the rectal toucher (RT) examination. Macroscopically, brownish-white masses were found showing a solid or solid-cystic pattern. Radiological examination can use transrectal ultrasound (TRUS), CT Scan and MRI. Histopathologically, prostate STUMP has five different patterns, namely the degenerative atypia pattern, hypercellular stroma pattern, phyllodes-type growth pattern, myxoid pattern, and epithelioid stromal pattern. Meanwhile, in PSS, there are histological patterns of storiform, epithelioid, fibrosarcomatous, and patternless growth patterns. Then PSS was subclassified into two, namely low grade and high grade tumors. Immunohistochemical examination showed immunoreactivity for CD34, PR, smooth muscle actin (SMA), desmin, HHF35, smooth muscle actin, vimentin and androgen receptors and negative for estrogen receptors, CD117 and S-100. The differential diagnosis is rhabdomyosarcoma, leiomyosarcoma, inflammatory myofibroblastic tumor, sarcomatoid carcinoma, benign prostate hyperplasia, smooth muscle tumor, gastrointestinal stromal tumor, and solitary fibrous tumor. Prognosis of prostate STUMP is better than that of PSS. Treatment of STUMP is currently unknown. Definitive resection can be performed taking into account the patient's age, treatment preference, and the size or size of the lesion. Treatment for PSS radical prostatectomy, cystoprostatectomy, or pelvic exenteration for local aggressive tumors.
\end{abstract}

\section{Introduction}

Stomal prostate tumor is a type of tumor that rarely occurs, which is about $0.1-0.2 \%$ of the total incidence of cancer in the prostate. Tumors in the stroma are classified into two groups, namely prostatic stromal tumors of uncertain malignant potential (STUMP prostate) and prostatic stromal sarcomas (PSS). The incidence of prostate STUMP was in patients between 27 and 83 years of age, with the mean patient age being 58 years and PSS occurring more frequently in men younger than 50 years. ${ }^{1,2}$

STUMP prostate and PSS have various similarities with other spindle cell tumors. Therefore, based on this, the compilers will discuss the definition, etiology, pathogenesis, clinical picture, radiological picture, histopathological picture, immunohistochemical examination and diagnosis similar to the two, which is useful for the accuracy of therapy in patients with this diagnosis. ${ }^{3}$

\section{Definition}

Stromal tumors in the prostate consist of STUMP prostate and PSS. Prostatic STUMP and PSS are rare mesenchymal tumors of the prostatic stromal, characterized by atypical and characteristic 
proliferation of the prostatic stroma, typically spindle cell tumors, differentiated by cellularity, mitotic index, cellular atypia, and necrosis. The pathological diagnosis of STUMP is sometimes disguised by the proliferation of the stroma present in BPH. Several cases of STUMP have also been reported to have turned malignant, namely into PSS. Meanwhile, there is no clear difference between PSS and STUMP because of the low incidence of these tumors ${ }^{4,5}$

\section{Etiology and pathogenesis}

The etiology and pathogenesis of STUMP are still uncertain, and no risk factors have been identified. However, there are several sources that explain the etiology / pathogenesis of STUMP and PSS based on origin, clonal and chromosomal abnormalities. PSS can occur de novo or in conjunction with a pre-existing prostatic stromal tumor (STUMP).2,6

Based on the origin, prostate STUMP and PSS are derived from the expression of the hormonal progesterone receptor $(\mathrm{PR})$ in the prostate mesenchyme, as well as the presence of an epithelial component with a phyllodes pattern that expresses PSA and PAP originating from prostatic acinar as a result of this anomalous or excessive stimulation that causes PSS or STUMP. Whereas on a clonal basis, STUMP differs slightly in the heterozygous pattern observed in the epithelial and stromal components of phyllodes tumors. The epithelial and stromal components of phyllodes tumors are neoplastic but have been suggested to have different clonal oringin formations. As for chromosomes, in prostate STUMP and PSS there are chromosomal abnormalities on chromosomes13,14 and $10.2,6$

\section{Epidemiology}

Prostate cancer is the most common malignancy in men, about 33\% in the United States in 2006. Prostate cancer is the third leading cause of cancer deaths, accounting for about $9 \%$ of all cancer deaths in men estimated in 2006.7

This specific prostate stromal tumor is a type of tumor whose incidence is very rare, about $0.1-0.2 \%$ of the total incidence of prostate cancer. Currently, there are only 100 reported cases of STUMP diagnosis, usually between 27 and 83 years of age, with a mean age of 58 years and the peak incidence occurs in the sixth and seventh decades. Only a fifth of the reported cases occur in men aged less than 50 years. Meanwhile, in the case of PSS, the incidence rate in men was relatively younger than 50 years, namely the range between 22 and 65 years, with an average age of 38.5 years. $2,6,8$

\section{Clinical features}

Patients with a diagnosis of prostate STUMP often present with complaints that lead to lower urinary tract obstruction and rectal discomfort, abnormal rectal toucher (RT) examination, namely enlarged \& hard prostate, hematuria, hematospermia, or elevated serum PSA levels.2,6

In patients with PSS, the main clinical manifestations are dysuria and pollakiuria. In addition, there were also abnormal RT examination results, namely an enlarged prostate, with a volume of $>145$ $\mathrm{ml}$, and felt hard or supple. On the PSA examination, the value remains at normal limits. ${ }^{2}$

\section{Macroscopic}

On macroscopic examination, STUMP appears brownish-white in color and shows a solid or solidcystic pattern with a smooth-walled cyst filled with fluid mixed with blood, mucus, or clear. ${ }^{1.6}$ Its size can range from a few centimeters to $0.7 \mathrm{~cm}$ to $18 \mathrm{~cm}$ and the weight ranges from 26 grams to 1044 grams. ${ }^{9}$

On the macroscopic examination of the PSS, the mass was gray, white, brown or yellow, solid and about 2 to $18 \mathrm{~cm}$ in size (Figure 13). For PSS with a phyllodes pattern, a cystic mass or yellowish white nudolar appears. 10

\section{Radiological Overview}

STUMP prostate can be identified through several radiological examinations, including transrectal ultrasound (TRUS), computer tomography (CT), and 
magnetic resonance imaging (MRI). On the TRUS examination it was found that the prostate was enlarged and well defined. CT examination of the prostate STUMP revealed heterogeneous prostate hypodensity with slightly irregular margins. On the MRI image, several masses showed hypointense on T1weighted MR images, while some parts showed hyperintensity. ${ }^{11}$

On the TRUS PSS examination, a very large volume, heterogeneous nodules infiltrating the prostate, and irregular margins are important characteristics of prostate sarcoma. A CT scan shows an enlarged prostate, the tumor can be round, lobular or irregular. However, usually necrosis and cystic changes in tumors often occur due to high malignancy and rapid growth. 8

On MRI examination, it resembles a multinodular, uneven mass located mainly within the central zone of the prostate and extending to the right periphery in the lower part of the central zone. The mass exhibits a homogeneous low signal intensity on T1-weighted imaging, and a heterogeneous high signal intensity with a pseudocapsule on T2-weighted echo-planar imaging $(E P I) .8$

\section{Histopathology}

In the histopathological examination of prostate STUMP, five different histological patterns were found, namely the degenerative atypia pattern, hypercellular stroma pattern, phyllodes-type growth pattern, myxoid pattern, and epithelioid stromal pattern. The most common histological pattern is the degenerative atypia pattern, which is $50 \%$ of cases. ${ }^{1}$ Meanwhile, the diagnosis of PSS is based on stromal infiltration, stromal cell proliferation, pleomorphism, with multiple mitosis, necrosis foci, and extraprostatic extension. Similar to STUMP, PSS also has several histological patterns, namely storiform, epithelioid, fibrosarcomatous, and patternless growth patterns. ${ }^{2,10}$

In the first pattern, or degenerative atypia pattern, there is a normal to slightly hypersellular stromal image with spindle cells showing degenerative atypia scattered around the benign prostate gland. The second histological pattern is referred to as the hypercellular stroma pattern. In this pattern there is a moderate hypercellular stroma, hypercellular bland fusiform stromal cells with eosinophilic cytoplasm surrounding the benign prostate gland. This pattern resembles fluorid mixed epithelial and stromal hyperplasia in benign prostate hyperplasia $(\mathrm{BPH})$, which differentiates it at the cellular level and larger stromal levels and has more eosinophilic cytoplasm.1,2,13,14

The third pattern is called the phyllodes-type growth pattern. This pattern was found to consist of a hypersellular stroma with or without atypia which has a similar pattern to the phyllodes tumor of the breast (previously referred to as phyllodes hyperplasia or phyllodes tumor). The fourth pattern is called the myxoid pattern. This pattern consists of broad stromal and bland stromal cells in the myxoid stroma.2,13,14

The microscopic examination of the PSS also revealed several patterns. The histological patterns are storiform, epithelioid, fibrosarcomatous, and patternless growth patterns below.

Stromal sarcomas are sub-classified into two, namely low grade and high grade. Low-grade tumors characterized by slightly atypical cells, prominent cellularity, sufficient mitosis, atypical nuclei, necrosis, and extraprostatic expansion indicate malignancy. The low grade PSS also shows the growth of epithelial cells from leaf-like glands with the stroma consisting of hypercellular spindle cells.2,10 Whereas high-grade tumors are characterized by hypersellularity, atypical cells, often accompanied by increased mitotic activity, occasional necrosis, and stromal overgrowth. 2,13

\section{Immunohistochemical examination}

Immunohistochemical examination of the stromal tumor in the prostate is performed in order to exclude other possible diagnoses, which may be similar in histopathological features. Immunohistochemical examination of a stromal tumor in the prostate shows positive reactivity for $\mathrm{CD} 34$, which can help differentiate it from other mesenchymal prostate 
tumors such as rhabdomyosarcoma or leiomyosarcoma. ${ }^{12}$

Besides CD34, STUMP \& PSS were also positive for PR immunohistochemical tests, smooth muscle actin (SMA), Desmin, HHF35, smooth muscle actin, vimentin and androgen receptors. However, immunohistochemical tests were negative for estrogen receptors, CD117 and $\mathrm{S}-100 .^{2}$

\section{Differential Diagnosis}

PSS and STUMP must be differentiated from other benign and malignant tumors. The differential diagnosis of specific stromal tumors in the prostate against other mesenchymal tumors, namely rhabdomyosarcoma (RMS), leiomyosarcoma (LMS), inflammatory myofibroblastic tumor (IMT), sarcomatoid carcinoma (SC), BPH, smooth muscle tumor (SMT), gastrointestinal stromal tumor (GIST), and solitary fibrous tumor (SFT). Based on the comparison of the histopathological features are as in table 1 below. ${ }^{2}$

Apart from being based on histopathological comparisons, the differential diagnosis of stromal tumors is also based on immunohistochemical examinations of other mesenchymal tumors. This comparison can be seen in the table below. 2

\section{Therapy}

The exact treatment approach for STUMP is currently unknown. Transurethral resection of the prostate is performed to relieve symptoms in the lower urinary tract. Definitive resection is performed on the basis of the patient's age, treatment preference, and size or size of the lesion. Usually, radical prostatectomy for men is relatively young and in early stage, but active surveillance is performed in elderly patients with lesions limited to biopsy and without a visible mass on imaging studies. For the advanced stage and metastases, the action and therapy given are not yet known. 2,13

Terapi pada PSS biasanya adalah tindakan radical prostatectomy, cystoprostatectomy, atau pelvic exenteration untuk tumor agresif lokal. Multimodal therapy yaitu termasuk kemoterapi berguna pada tumor fase lanjut dan tumor yang sudah mengalami metastasis. Remisi lengkap dilaporkan pada PSS yang metastasis ke paru-paru menggunakan anthracycline and alkylating agent-based regimen diikuti oleh metastektomi. ${ }^{2,10}$

\section{Prognosis}

Prostate STUMP generally has a good prognosis because the tumor is confined to the prostate $\&$ is usually not aggressive, but sometimes recurs rapidly after resection, and a small proportion (rarely) develop PSS. STUMP prostate has a faster growth than BPH. Poor prognosis with a $20 \%$ risk of death within the first year and widespread metastases to the bones, liver, and lungs. 2,13

In $65 \%$ of cases, PSS was reported to be recurrent with a mean time of 2 years after treatment. PSS is locally aggressive and can directly affect the seminal vesicles, bladder, large intestine, pelvis and perineum. PSS can also metastasize, that is, it is more common in high-grade PSS. The most common reported sites for metastases include the lungs (most commonly), bone, abdominal wall, and retroperitoneum. 2,10 

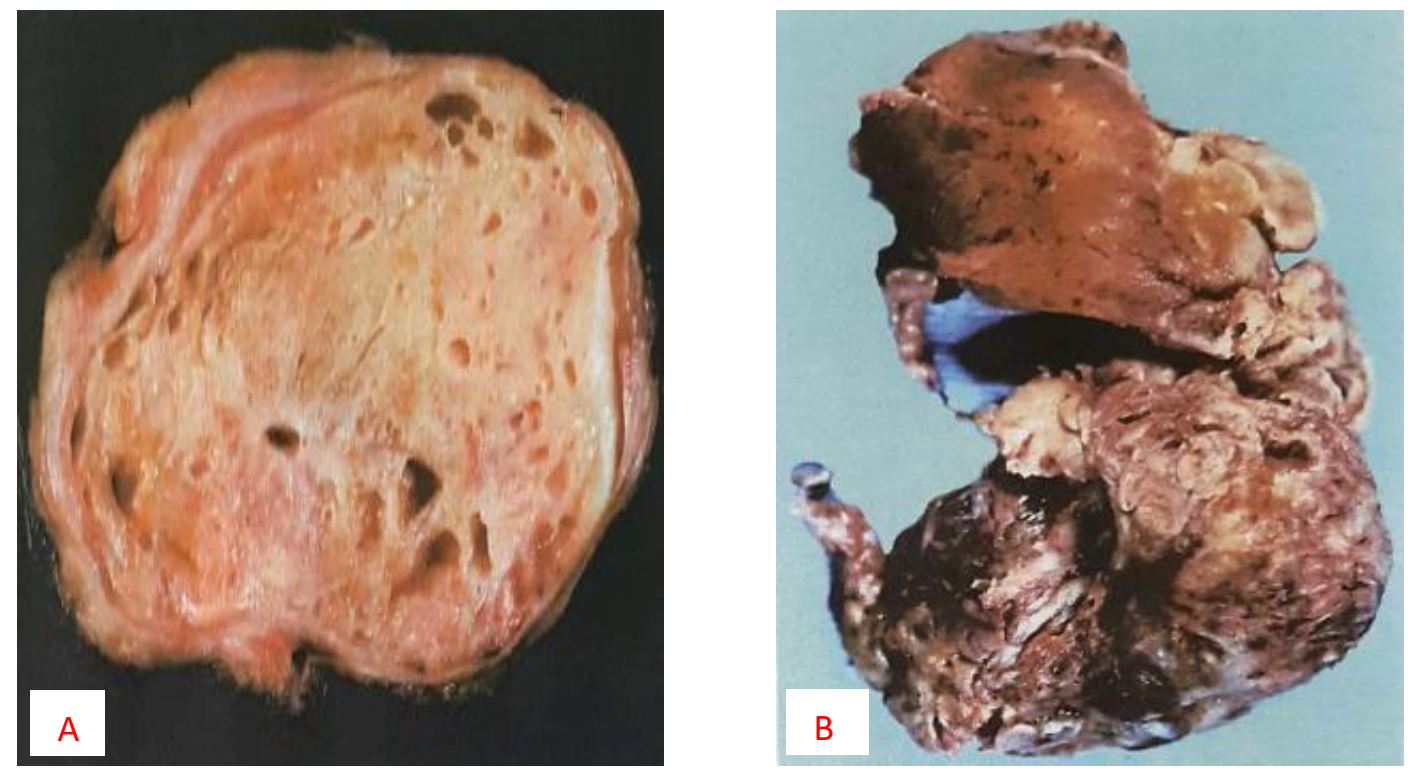

Figure 1. Macroscopic stromal tumor of the prostate. A. STUMP prostate with large well-circumscribed nodule of varying size cyst. B. Solid and cystic mass, with focal bleeding. ${ }^{10}$
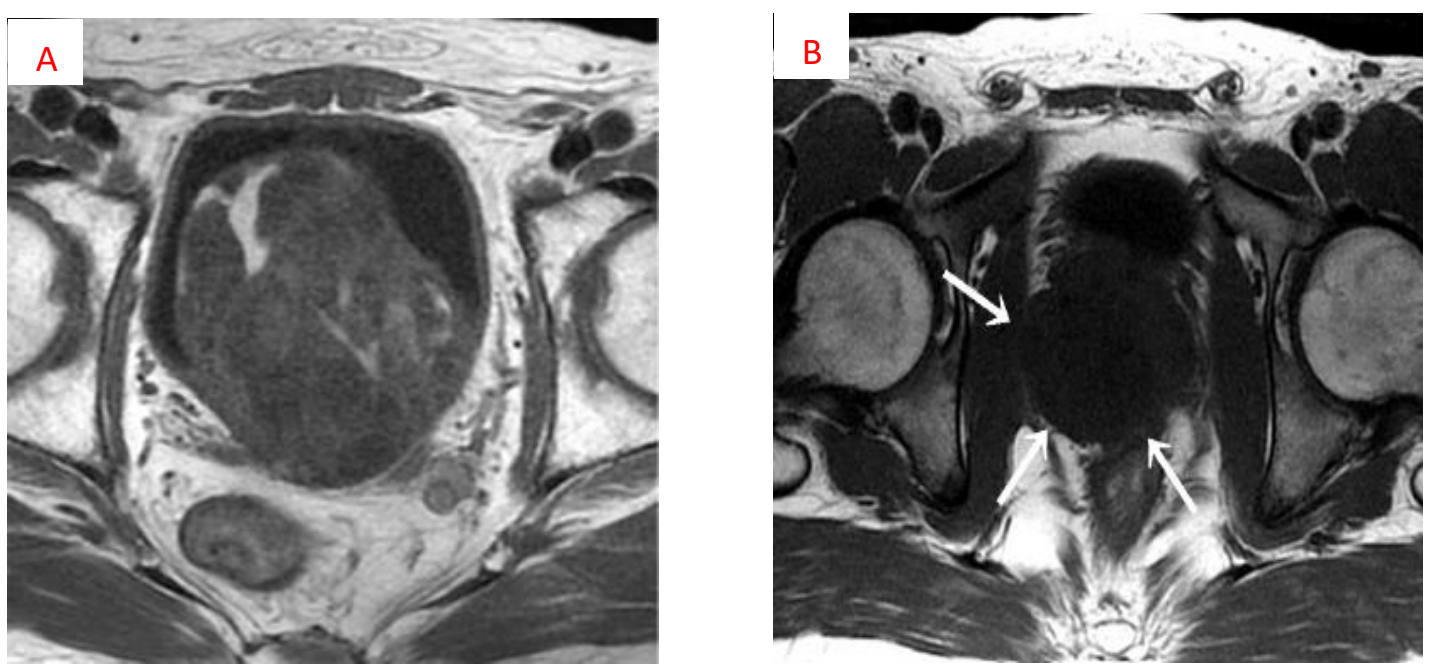

Figure 2. MRI examination of a stromal tumor in the prostate. A. MRI STUMP prostate. demonstrated heterogeneous hypointensity on T1-weighted MR images. whereas some sections show hyperintensity. B. T1-weighted axial image showing a mass located centrally and on the right side of the prostate with a slightly low homogeneous signal intensity compared to the left side of the prostate (arrows). $.8,12$ 

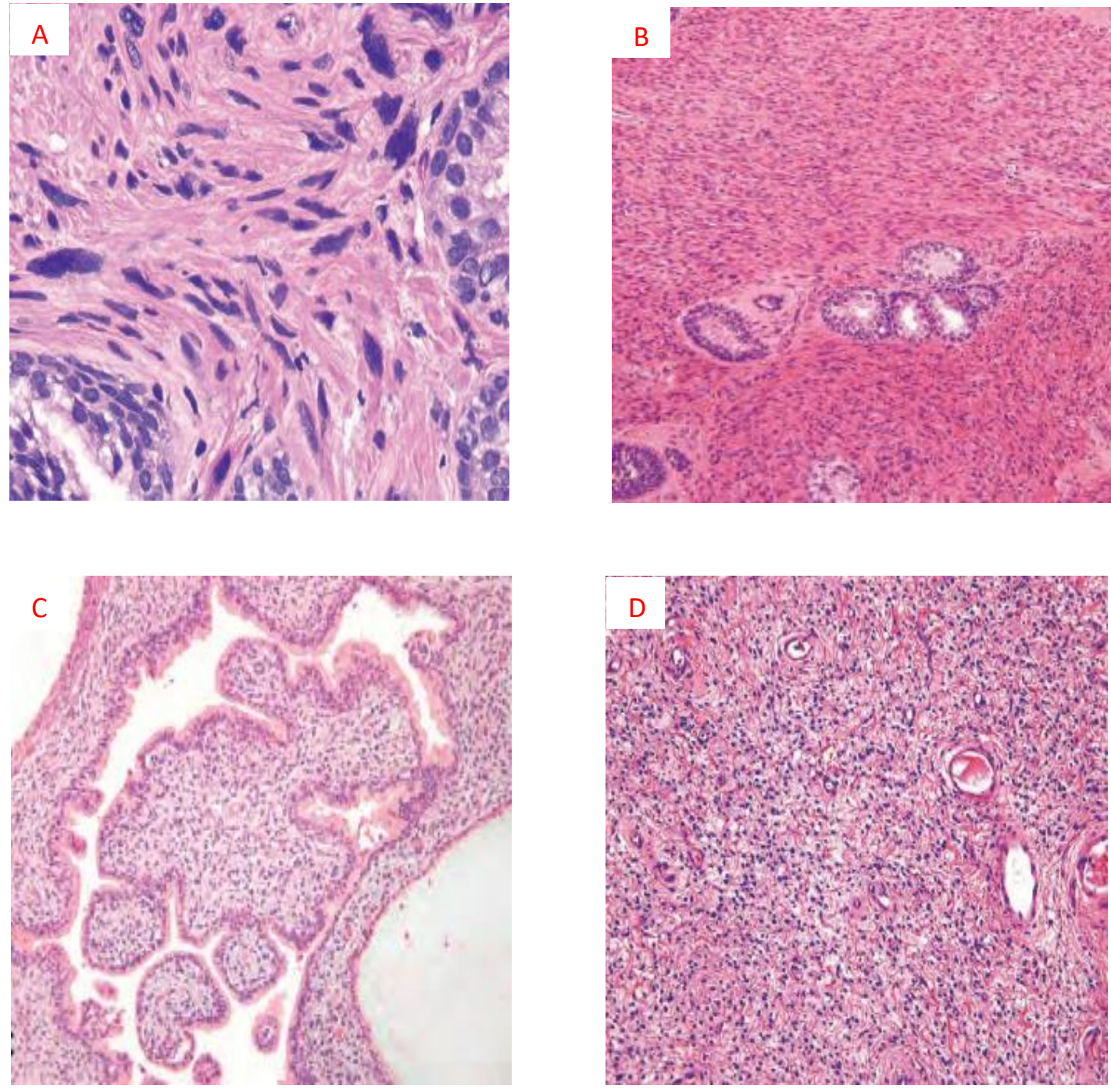

Figure 3. Histological pattern of prostate STUMP. A. Degenerative atypia pattern. Enlarged, degenerative pleomorphic nucleus. The nucleus lacks well-defined chromatin and little features of mitosis. B. STUMP with a pronounced hypersellular stroma, consisting of cells with an eosinophilic cytoplasm. C. Of note, relatively bland cells in the myxoid stroma form leaf-like invaginations into benign prostate glands that resemble phyllodes mammae tumors. D. Myxoid STUMP. These lesions consist of a hypersellular myxoid stroma without nodularity.2,13
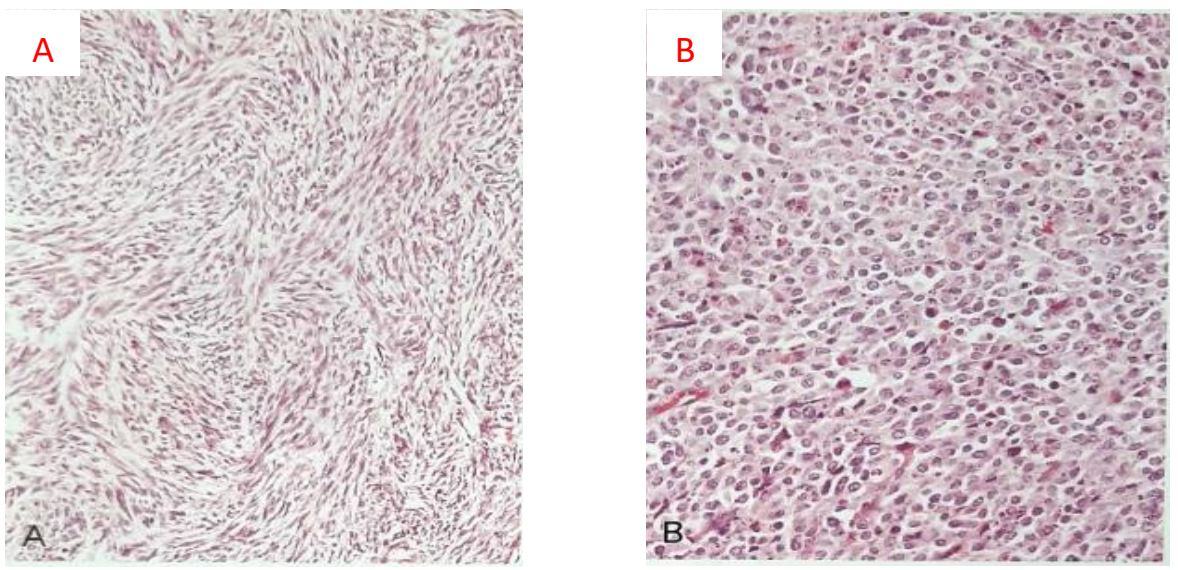

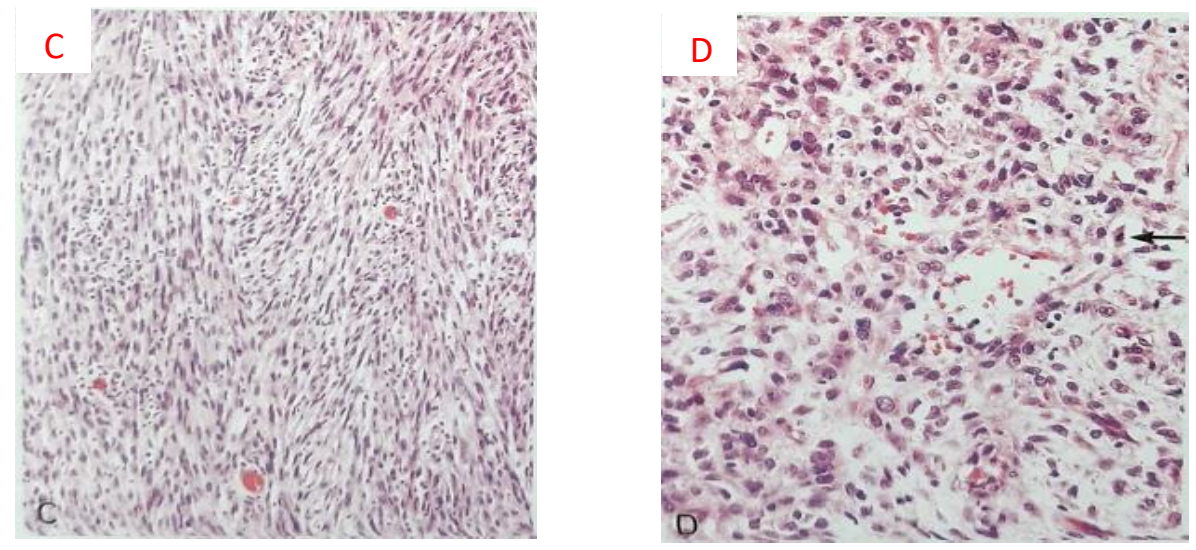

Figure 4. Histological pattern of PSS. A. Storiform. B. Epithelioid. C. Fibrosarcomatous. D. Patternless growth patterns, with a number of mitotic figures (arrows). ${ }^{10}$
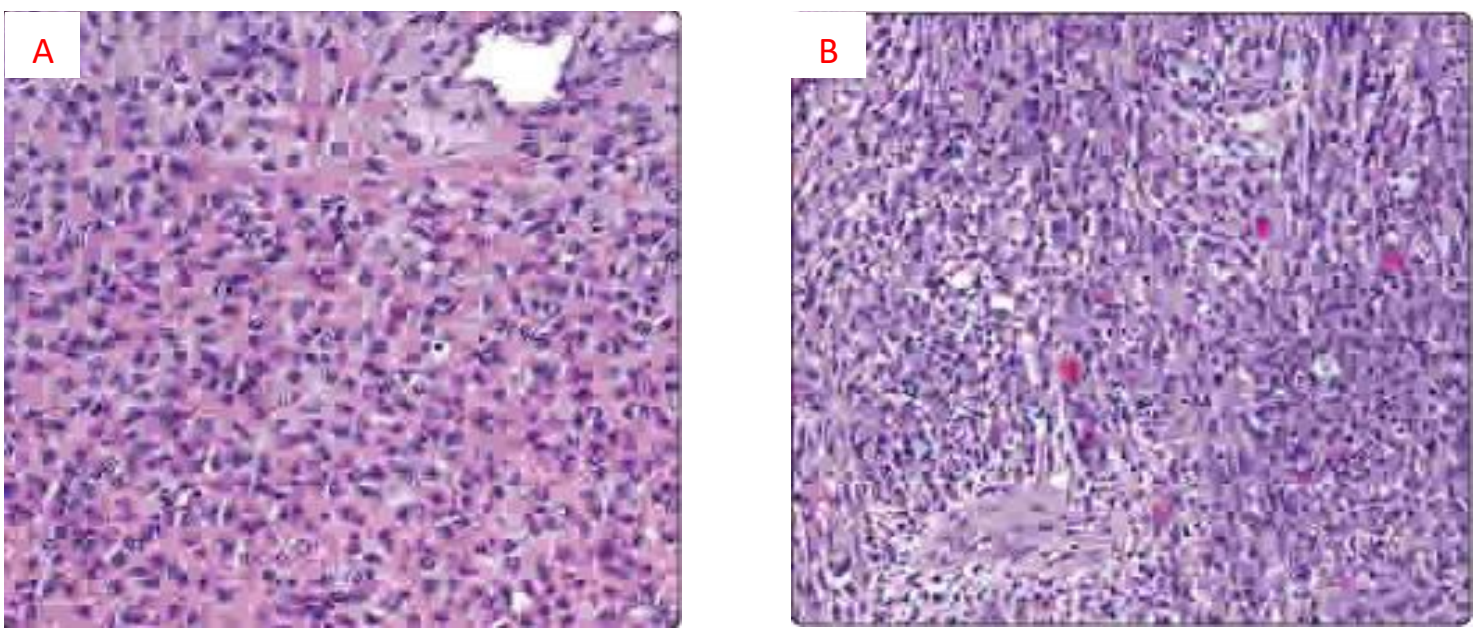

Figure 5. A. Low grade PSS. Hypersellular epithelioid cell appearance and moderate atypic nucleus present. B. High grade PSS. A. Spindle cells with focal fascicular growth pattern. ${ }^{2}$
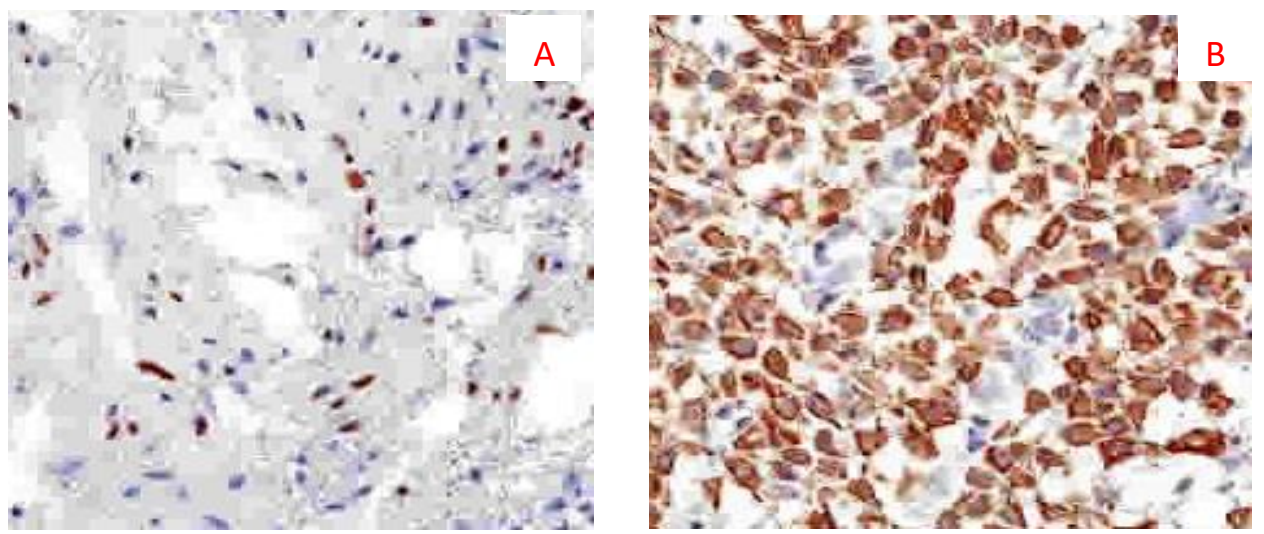


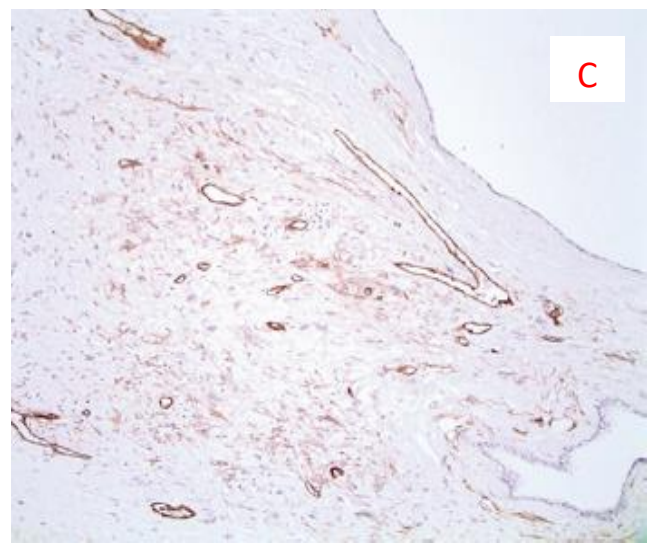

Figure 6. A. Immunohistochemical examination results. A. Overview of PR immunohistochemical results. B. Overview of immunohistochemical results of SMA. C. Overview of immunohistochemical results CD34.2,15

Table 1. Differential diagnosis based on histopathological features ${ }^{2}$

\begin{tabular}{ll}
\hline Differential diagnosis & \multicolumn{1}{c}{ Histopathological features } \\
\hline RMS & RMS consists of primitive or undifferentiated cells to large round cells or spindled \\
& rhabdomyoblasts. \\
LMS & Well-defined fascicles and smooth muscle cells arranged interlacing with atypical \\
& nucleus arrangement, mitotic activity, and necrosis; infiltrative \\
BMI & Reactive-appearing uniform myofibroblastic cells in loose myxoid stroma with fine \\
& chromatin, prominent nucleoli, and mitotic activity \\
SC & High-grade spindle cells \pm heterologous elements associated with epithelioid \\
BPH & components (adenocarcinoma) \\
& Multinodular growth bland cells with a large number of capillaries show condensed \\
GIST & stromal cells around the blood vessels \\
SFT & The spindle cells form a fecicular pattern with perinuclear vacuoles \\
& Bland spindle cells arranged haphazardly with the cytoplasm slightly surrounded by \\
& thick collagen (like keloids) and small blood vessels to hemangiopericytomatous \\
& (staghorn)
\end{tabular}

Table 2. Differential diagnosis based on immunohistochemistry ${ }^{2}$

\begin{tabular}{|c|c|c|c|c|c|c|c|c|c|}
\hline $\begin{array}{l}\text { Differential } \\
\text { diagnosis }\end{array}$ & CD34 & SMA & Desmin & ALK1 & CD117 & $\mathbf{P R}$ & Pancreatine & $\begin{array}{c}\text { PSA / } \\
\text { PAP }\end{array}$ & Myogenin \\
\hline STUMP & + & $-1+$ & $-/+$ & - & - & + & - & - & - \\
\hline RMS & - & + & + & - & - & - & - & - & + \\
\hline SMT & - & + & + & - & - & $+/-$ & $+1-$ & - & - \\
\hline BMI & - & + & + & $+1-$ & $+1-$ & - & $+1-$ & - & - \\
\hline $\mathrm{SC}$ & - & $-1+$ & $-1+$ & - & - & - & $+* /-$ & $+* /-$ & - \\
\hline PSS & + & $-1+$ & $-/+$ & - & - & + & - & - & - \\
\hline GIST & + & $+1-$ & $+1-$ & - & + & - & - & - & - \\
\hline SFT & + & - & - & - & - & $+/-$ & - & - & - \\
\hline
\end{tabular}

* $=$ more in a positive direction in well-differentiated carcinoma cells. 


\section{References}

1. Cheville J, Algaba F, Epstein JI, Lopez BA. Mesenchymal tumours. In: Moch $\mathrm{H}$, Peter AH, Thomas MU, Victor ER, editors. WHO classification of tumours of the urinary system and male genital organs. 4th ed. Lyon: IARC; 2016. p. $175-6$.

2. Paner GP. Stromal and mesenchymal tumors of prostate. In: Amin MB, Satish KT, editors. Diagnostic pathology genitourinary. $2^{\text {nd }}$ ed. Philadelphia: Elsevier; 2016. p. 690-705.

3. Mokhtari M, Maryam H, Shahrzad YP. The prevalence of prostatic stromal tumor of uncertain malignant potential in specimens diagnosed as prostatic hyperplasia. Arch Iran Med 2016; 19(7):488-90.

4. Matsuyama S, Takahiro N, Shohei K, Chikashi S, Yuko N, Akio U, et al. Case report prostatic stromal tumor of uncertain malignant potential which was difficult to diagnose. Case Rep Urol 2015; 52(1):1-5.

5. Zynger DL, Anil VP. Demos surgical pathology guides. Prostate pathology. New York: Demos Medical; 2015. p. 164-7.

6. Epstein JI, George JN. Biopsy interpretation series: biopsy interpretation of the prostate. $5^{\text {th }}$ ed. Philadelphia: Wolters Kluwer; 2015. p. 333-42.

7. Cunha GR, Chad MV, Dylan I, William AR, Barry GT, Mei C, et al. Development of the human prostate. J Diff. 2018; 8:1-22.
8. Yang W, Ailian L, Jingjun W, Miao N. Prostatic stromal sarcoma: a case report and literature review. Medicine 2018; 97:18.

9. Johnson MH, Ballentine HC. Stromal tumor of uncertain malignant potential (STUMP) with PSA >500 ng/ml. Urol Case Rep 2015; 3(5):175-7.

10. Epstein JI, Antonio LC, Peter AH. Afip atlas of tumor pathology. Tumors of the prostate gland, seminal vesicles, penis, and scrotum. 4th ed. Washington: American Registry of Pathology; 2011. p. 323-32.

11. Yamazaki M, Kotaro Y, Noboru T, Keiko K, Norihiro $\mathrm{H}$, Shinichi $\mathrm{H}$, et al. CT and MRI findings of a stromal tumour of uncertain malignant potential of the prostate. Eur J Radiol Open 2020; 24(7):100233.

12. Pisters LL. Prostate sarcomas and squamous cell carcinomas. In: Pagliaro L, editor. Rare genitourinary tumors. 1 st ed. Rochester: Springer; 2016. p. 223-4.

13. Tavora F, Oleksandr N, Jonathan IE. Review: mesenchymal tumours of the bladder and prostate: an update. Pathology 2013; 45(2):10415.

14. Epstein IL, George JN. Differential diagnoses in surgical pathology: genitourinary system. $1^{\text {st }}$ ed. Philadelphia. Wolters Kluwer; 2014. p. 150-6

15. Lu Y, Weiping H. Prostatic Stromal Tumor of Uncertain malignant Potential; A Clinicopathologic Study Of Two Case and revie of The Literature. Int J Clin Exp Pathol 2016; 9(9): 9503-7 